\title{
Multidimensional analysis of gene expression reveals TGFB1I1-induced EMT contributes to malignant progression of astrocytomas
}

\author{
Yanwei Liu ${ }^{1,6, *}$, Huimin Hu${ }^{1,6, *}$, Kuanyu Wang ${ }^{4}$, Chuanbao Zhang ${ }^{2,6}$, Yinyan Wang ${ }^{2,6}$, \\ Kun Yao ${ }^{5,6}$, Pei Yang ${ }^{2,6}$, Lei Han ${ }^{3,6}$, Chunsheng Kang ${ }^{3,6}$, Wei Zhang ${ }^{1,2,6}$, Tao Jiang ${ }^{1,2,6,7,8}$ \\ ${ }^{1}$ Department of Molecular Neuropathology, Beijing Neurosurgical Institute, Capital Medical University, Beijing, China \\ ${ }^{2}$ Department of Neurosurgery, Beijing Tiantan Hospital, Capital Medical University, Beijing, China \\ ${ }^{3}$ Laboratory of Neuro-Oncology, Tianjin Neurological Institute, Tianjin Medical University, Tianjin, China \\ ${ }^{4}$ Department of Neurosurgery, The First Affiliated Hospital of Dalian Medical University, Dalian Medical University, Dalian, \\ China \\ ${ }^{5}$ Department of Molecular Neuropathology, Beijing Sanbo Brain Hospital, Capital Medical University, Beijing, China \\ ${ }^{6}$ Chinese Glioma Cooperative Group (CGCG), China \\ ${ }^{7}$ China National Clinical Research Center for Neurological Diseases, China \\ ${ }^{8}$ Center of Brain Tumor, Beijing Institute for Brain Disorders, Beijing, China \\ *These authors contributed equally to this work
}

Correspondence to:

Jiang Tao, e-mail: jiangtao_369@163.com

Zhang Wei, e-mail: zhangwei_vincent@126.com

Keywords: Astrocytomas, Malignant progression, Gene expression, TGFB1।1, EMT

Received: April 28, $2014 \quad$ Accepted: September 24, $2014 \quad$ Published: December 31, 2014

\section{ABSTRACT}

Malignant progression of astrocytoma is a multistep process with the integration of genetic abnormalities including grade progression and subtypes transition. Established biomarkers of astrocytomas, like IDH1 and TP53 mutation, were not associated with malignant progression. To identify new biomarker(s) contributing to malignant progression, we collected 252 samples with whole genome mRNA expression profile [34 normal brain tissue (NBT), 136 grade II astrocytoma (AII) and 82 grade III astrocytoma (AIII)]. Bioinformatics analysis revealed that EMT-associated pathways were most significantly altered along with tumor grades progress with up-regulation of 17 genes. Up-regulation of these genes was further confirmed by RNA-sequencing in 128 samples. Survival analysis revealed that high expression of these genes indicates a poor survival outcome. We focused on TGFB1I1 (TGF- $\beta 1$ induced transcript 1 ) whose expression correlation with WHO grades was further validated by qPCR in 6 cell lines of different grades and 49 independent samples (36 AIIs and 13 AIIIs). High expression of TGFB1I1 was found associated with subtype transition and EMT pathways activation. The conclusion was confirmed using immunohistochemistry in tissue microarrays. Studies in vitro and in vivo using TGF- $\beta 1$ and TGFB1I1 shRNA demonstrated that TGFB1I1 is required for TGF- $\beta$ stimulated EMT that contributes to malignant progression of astrocytomas.

\section{INTRODUCTION}

Astrocytomas are the most prevalent primary brain tumor and characterized by invasive and rapid growth. Tumor cells achieve rapid invasion and long-distance migration from the tumor mass into the normal brain tissue, and these processes are responsible for tumor recurrence.
The invasion of tumor cells increases gradually with tumor grade progress. At present, histomorphology remains the only criterion for the diagnosis of astrocytomas. According to the world health organization (WHO) standards, the grading is based on the presence or absence of nuclear atypia, mitosis, vascular proliferation, and necrosis [1]. Low grade astrocytomas with characteristic of nuclear 
atypia or mitosis have longer survival but ultimately transform to a higher grade tumor with increasing malignancy (vascular proliferation or necrosis). However, there also exists different malignant degree on the equal grade that corresponds to different prognosis [2, 3]. Therefore, the malignant phenotype of astrocytomas cannot be well characterized by the current grading system.

Advances in molecular genetics are challenging the traditional morphological categorization of tumors. The theory that glioma is a result of polygenic disorder is increasingly being recognized. Gene expression abnormalities are associated with progression of gliomas and can differentiate not only among histologic subtypes but also between low and high grade gliomas [4, 5]. Molecular alterations on primary GBM (arising de novo) have been studied thoroughly. But II-III grade astrocytomas and secondary GBM (arising from lower-grade gliomas) are less well-characterized in tumor formation and progression. Major findings in low grade astrocytoma include frequent activating mutations in $I D H 1$ and TP53, and $R B 1$ inactivation [6-8]. Recently, Jiao et al. found that ATRX inactivation is linked to mutations in TP53 and IDH1 in low grade gliomas [9]. These classical alterations were generally considered as the earliest genetic abnormalities in the development of astrocytomas. But the high frequency of these alterations are already present in low grade gliomas (AII) and the frequency does not increase (even decrease) in high grade gliomas (AIII or GBM) suggesting that they might not associated with malignant progression of astrocytomas. More importantly, there also exists another malignant progression on the equal grade of tumors (subtypes transition). Different subtypes have different malignant phenotypes that were also resulted from many genetic alterations $[3,10]$. Therefore, discovery of new driver markers would help to understand molecular mechanisms of astrocytomas progression.

The aim of the present study was to identify genetic alterations involved in the malignant progression of astrocytomas. Secondary GBM not to be included in the study due to patients undergo a second operation or chemoradiotherapy that might affect gene expression [11]. The established biomarkers of astrocytomas, like IDH1 and TP53 mutation, were not associated with malignant progression though could predict survival in the present or previous studies [12]. To identify new biomarker(s), we collected and analyzed 252 samples with whole genome expression profile (34 NBTs, 136 AIIs and 82 AIIIs). The candidate genes which were up-regulated with increasing tumor grades were further confirmed on 128 samples with RNA-sequencing (57 AIIs and 71 AIIIs). Finally, we focused on TGFB1I1 which was a TGF- $\beta 1$ induced transcription factor involved in the EMT process. In addition, TGFB1I1 might be associated with subtype transition and could be used as serviceable marker for mensenchymal astrocytoma. The transcriptional and the protein level of TGFB1I1 were further validated on additional samples by qPCR and IHC. Finally, studies in vivo and in vitro demonstrated that TGF- $\beta 1$-inducible TGFB1I1 is required for regulation of cell migration and invasion and is an important regulator of TGF- $\beta$ stimulated EMT. This finding is new opportunity for understanding the fundamental basis for malignant progression of astrocytomas and also provide novel interfering target for shutting down astrocytomas progression.

\section{RESULTS}

\section{The established biomarkers were not associated with grade progression.}

At present, many reliable molecular markers, such as TP53 and IDH1 mutation, have been accepted as early alterations in astrocytomas development [6, 7]. In this study, we asked whether these master markers are changed with increasing tumor grades. By application of various detection techniques, we counted PTEN mutation, IDH1 R132 mutation, 1p19q loss, TP53 mutation, $M G M T$ promoter methylation and EGFR amplification in CGGA database (Table 1). We found

Table 1: Established biomarkers in different grade astrocytomas

\begin{tabular}{|l|l|l|l|l|}
\hline Variables & NBT & $\begin{array}{l}5 / 140 \\
(3.5 \%)\end{array}$ & $\begin{array}{l}3 / 17 \\
(17.6 \%)\end{array}$ & $<0.05$ \\
\hline PTEN mutation & NA & $\begin{array}{l}131 / 182 \\
(80 \%)\end{array}$ & $\begin{array}{l}13 / 33 \\
(39.4 \%)\end{array}$ & $<0.05$ \\
\hline IDH1 mutation & NA & $\begin{array}{l}12 / 217 \\
(5.5 \%)\end{array}$ & $\begin{array}{l}6 / 40 \\
(15 \%)\end{array}$ & $>0.05$ \\
\hline Ip19q loss & $0 / 6$ & $\begin{array}{l}67 / 149 \\
(50.0 \%)\end{array}$ & $\begin{array}{l}5 / 18 \\
(27.8 \%)\end{array}$ & $<0.05$ \\
\hline TP53 mutation & NA & $\begin{array}{l}7 / 23 \\
(30.4 \%)\end{array}$ & $\begin{array}{l}15 / 24 \\
(62.5 \%)\end{array}$ & $<0.05$ \\
\hline MGMT methylation & NA & $\begin{array}{l}5 / 217 \\
(2.3 \%)\end{array}$ & $\begin{array}{l}2 / 40 \\
(5 \%)\end{array}$ & $>0.05$ \\
\hline EGFR amplification & $0 / 6$ & & & \\
\hline
\end{tabular}


that PTEN mutation and $M G M T$ promoter methylation are significantly increased with increasing tumor grade from $3.5 \%$ and $30.4 \%$ in AII to $17.6 \%$ and $62.5 \%$ in AIII. 1p19q loss and EGFR amplification which were mainly identified in oligodendrogliomas and primary GBM were not significantly different in different grades of astrocytoma. However, the highest alterations, IDH1 and TP53 mutation, were significantly decreased from $80 \%$ and $50 \%$ in AII to $39.4 \%$ and $27.8 \%$ in AIII. These data demonstrated that PTEN mutation might play driver role in grade progression of astrocytomas, but this alteration was only observed in a small minority of patients (4\%). The data that high frequency of IDH1 and TP53 mutation are already present in AII and the frequency does not increase (even decrease) in AIII suggests that they might be not associated with malignant progression of astrocytomas, especially in progression from AII to AIII.

\section{Significant changes in gene expression during grade progression of astrocytoma}

To identify new gene(s) contributing grade progression, we compared genome expression between NBT, AII and AIII. 252 samples with gene expression profile were obtained from our institution (CGGA: 5 NBTs, 58 IIAs and 8 IIIAs) and 2 external independent databases of glioma (GSE16011: 8 NBTs, 13 IIAs and 16 IIIAs; REMBRANDT: 21 NBTs, 65 AIIs and 58 AIIIs) (Figure-1A). A total of 29421 probes (19416 genes), 40547 probes (19596 genes) and 40547 probes (19596 genes) were available in CGGA, GSE16011 and REMBRANDT databases, respectively. To avoid discrepancies due to different platforms, the data were analyzed separately within each database. After overlapping the analyzed data, a total of 1299 up-regulated genes and 1031 downregulated genes were identified in AII compared with NBT (step1). 378 up-regulated and 493 down-regulated genes were identified in the step2 from AII to AIII (Figure-1B, supplementary table 2). To avoid any confusion in the data induced by one gene with more than one probe, the probes were consistent from NBT to AII, to AIII.

To further understand the changes in differentially genes and pathways of astrocytomas, Gene-set enrichment analysis were performed using a comprehensive set of functional annotation tool (The Database for Annotation, Visualization and Integrated Discovery, DAVID) [13]. As illustrated in Figure-1C, up-regulated gene expression profiles in AII, in comparison to NBT, were more strongly enriched in pathways related to cancer (sustained angiogenesis, VEGF signaling, evading apoptosis, and proliferation) and regulation of actin cytoskeleton, TGF- $\beta$-signaling pathway and glioma pathway. Similarly, pathways in cancer and cell adhesion molecules (CAMs) are also the main up-regulated pathways in AIII as compared to AII. The up-regulated pathways (actin cytoskeleton, adhesion molecules and TGF- $\beta$ ) suggested that grade progression of astrocytomas might result from obtaining the abilities of cell's invasion, adhesion, and movement. Overall, these differential pathways might contribute to an understanding of the molecular determinants that drive grade progress of astrocytomas.

\section{Driver genes in the entire process of malignant progression were associated with patient prognosis}

To address the molecular foundations of the entire process of grade progression, the differentially expressed genes were overlapped between step 1 and step 2 in three databases and finally 23 up-regulated and 6 down-regulated candidate genes were identified with a gradual deregulation from NBT to AII, to AIII $(p<0.05)$ (Figure-2A, supplementary table 2). We applied the classification system of TCGA to our CGGA samples [10, 14] and found all of neural subtype (5/5 NBTs, 100\%) were categorized into NBT. Proneural subtype, not found in NBT and AIII, was the highest percentage of AII (21/58, $36.2 \%$ ). Mensenchymal and classical subtypes formed an increasing proportion of astrocytomas with increasing grades $(0 \%$ in NBT, $34.5 \%$ in AII and $50 \%$ in AIII). The same distribution of subtypes was also found on GSE16011 and REMBRANDT databases (supplementary Figure-1A). This finding indicates that these candidate genes might also contribute to the subtype transition.

Surprisingly, Kaplan-Meier survival analysis found that almost all of these driver genes were associated with patients' prognosis, in spite of not reaching statistical significance in some genes (Figure-2B). However, except for KPS, cox repression analysis showed that there were no significant correlation between patient survival and age, sex, TP53 mutation and even IDH1 mutation and 1p19q loss (Supplementary Table 3). The median follow-up period for all 58 IIA patients of CGGA was 49.5 months (range, 5-70.1 months). In spite of not reaching statistical significance in some candidate genes, the prognosis trends were pretty obvious and even startlingly consistent in CGGA and GSE16011 databases (Supplementary Figure-1B) that high expression of up-regulated gene indicates a poor survival whereas high expression of down-regulated gene indicates a favorable survival, respectively.

\section{Candidate genes were further confirmed by RNA-sequencing and validated by qPCR}

The expression levels of the above candidate genes were projected into 2 independent RNA sequencing databases of glioma (CGGA: 35 AIIs and 13 AIIIs; TCGA: 22 AIIs and 58 AIIIs). 26 of the 29 candidate genes were confirmed in our CGGA database and 17 were further confirmed in TCGA database (Figure-3A and 3B). Most 
A

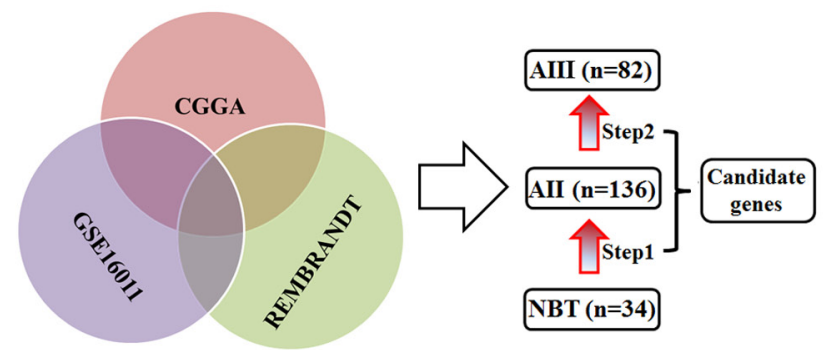

B
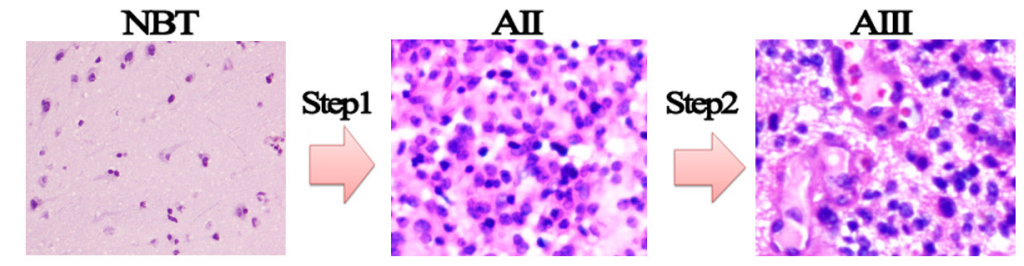

Differential genes - up 1299

-up $\quad 378$

-down 493

C

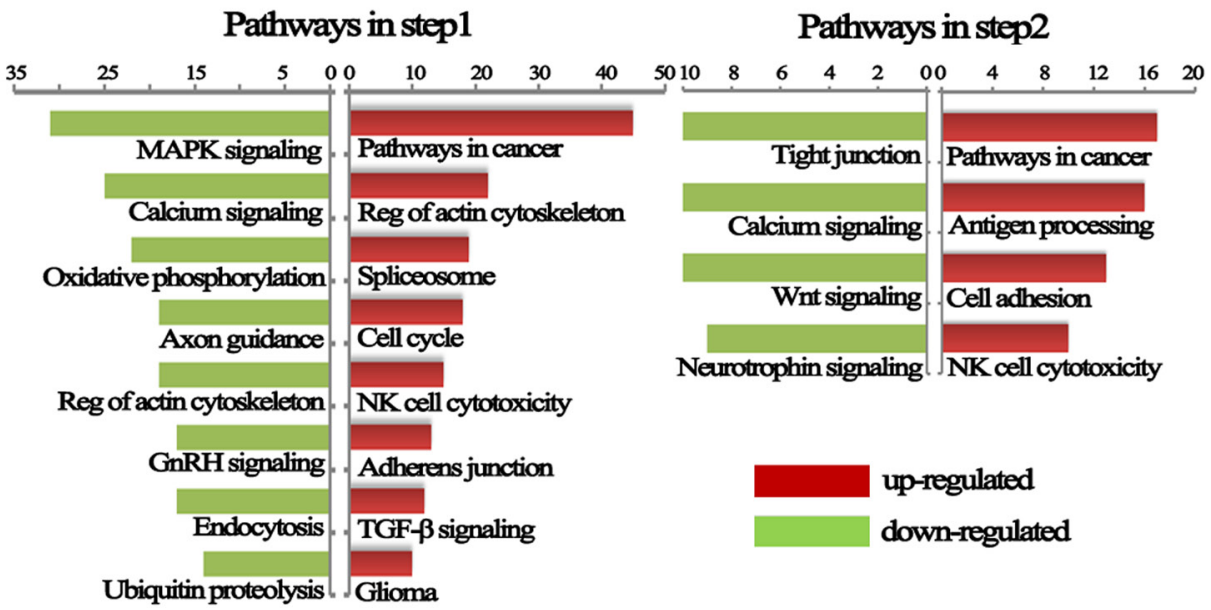

Figure 1: Changes in genes expression from NBT to grade II and grade II to grade III astrocytomas. (A) Differential genes were obtained from overlapping CGGA, GSE16011 and REMBRANDT databases. (B) A hematoxylin and eosin stained section was performed to determine the pathological type and grade and dysregulated genes were divided into up-regulated and down-regulated during malignant progression of astrocytomas. (C) KEEG pathways analysis performed using these differential expression genes on the DAVID website.

of these up-regulated genes, C1QA,CKLF, DTYMK, DUSP12, EDEM2, GPX7, KDELR2, KIAA0101, NRM, PCNA, PLSCR1, POLH, SMARCE1 and TGFB1I1, were identified in the malignant progression of a variety of tumors and contributes as an indicator for unfavorable prognosis [15-17].

Finally, we selected the top 3 survival associated genes, GYS1, TGFB1I1 and GABRA3, for validation by qPCR in 6 glioma cell lines (HA and H4, human astrocytes and astrocytoma cell line; N1 and N15, primary culture AII cells; N18, primary culture grade II oligodendroastrocytoma; N14, primary culture grade III oligodendroastrocytoma cell) and additional 49 samples (36 AIIs and 13 AIIIs). Finally, the mRNA expression level of TGFB1I1 was the best and most consistent with the above results that increasing expression was accompanied by increasing tumor grades (Figure-3C and 3D). TGFB1I1 was first identified as a TGF- $\beta$-inducible gene, and is a member of focal adhesion adaptor proteins. TGF- $\beta$-inducible TGFB1I1 has also been shown to function as an oncogene by inducing EMT to promote invasion in cancer cells $[17,18]$. More importantly, the up-regulated genes in astrocytomas mostly enriched in EMT associated signaling pathways (actin cytoskeleton, adhesion molecules and TGF- $\beta$ signaling), suggesting that TGFB1I1-inducible EMT might be involved in the malignant progression of astrocytomas. 
A

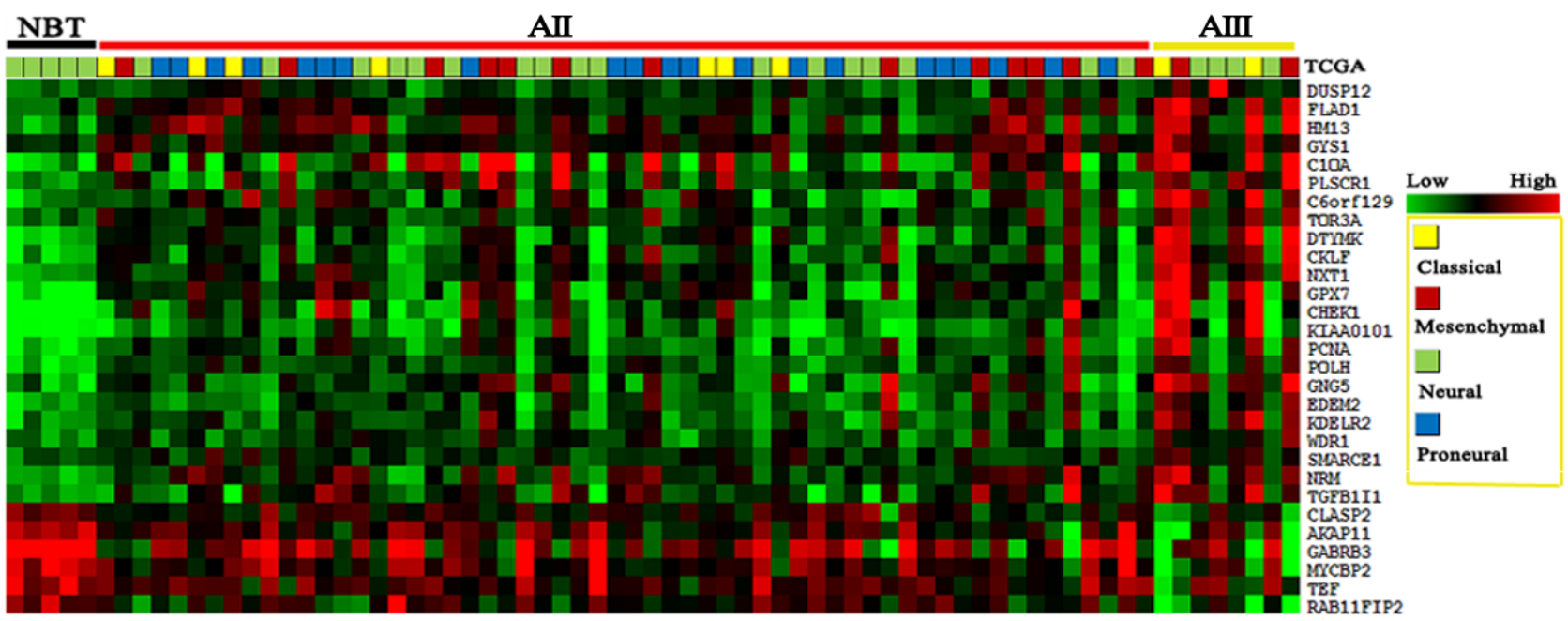

B
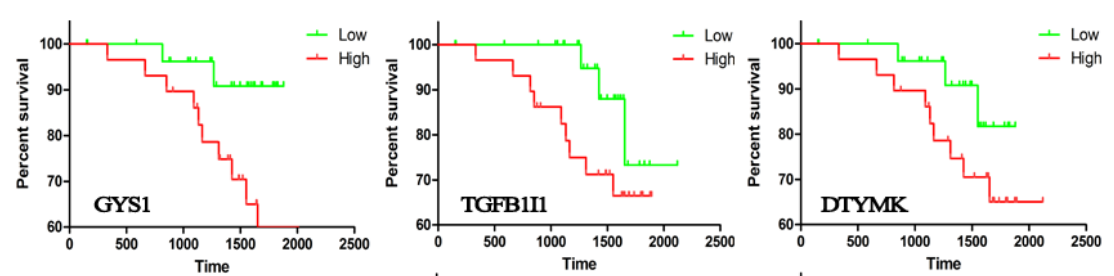

C
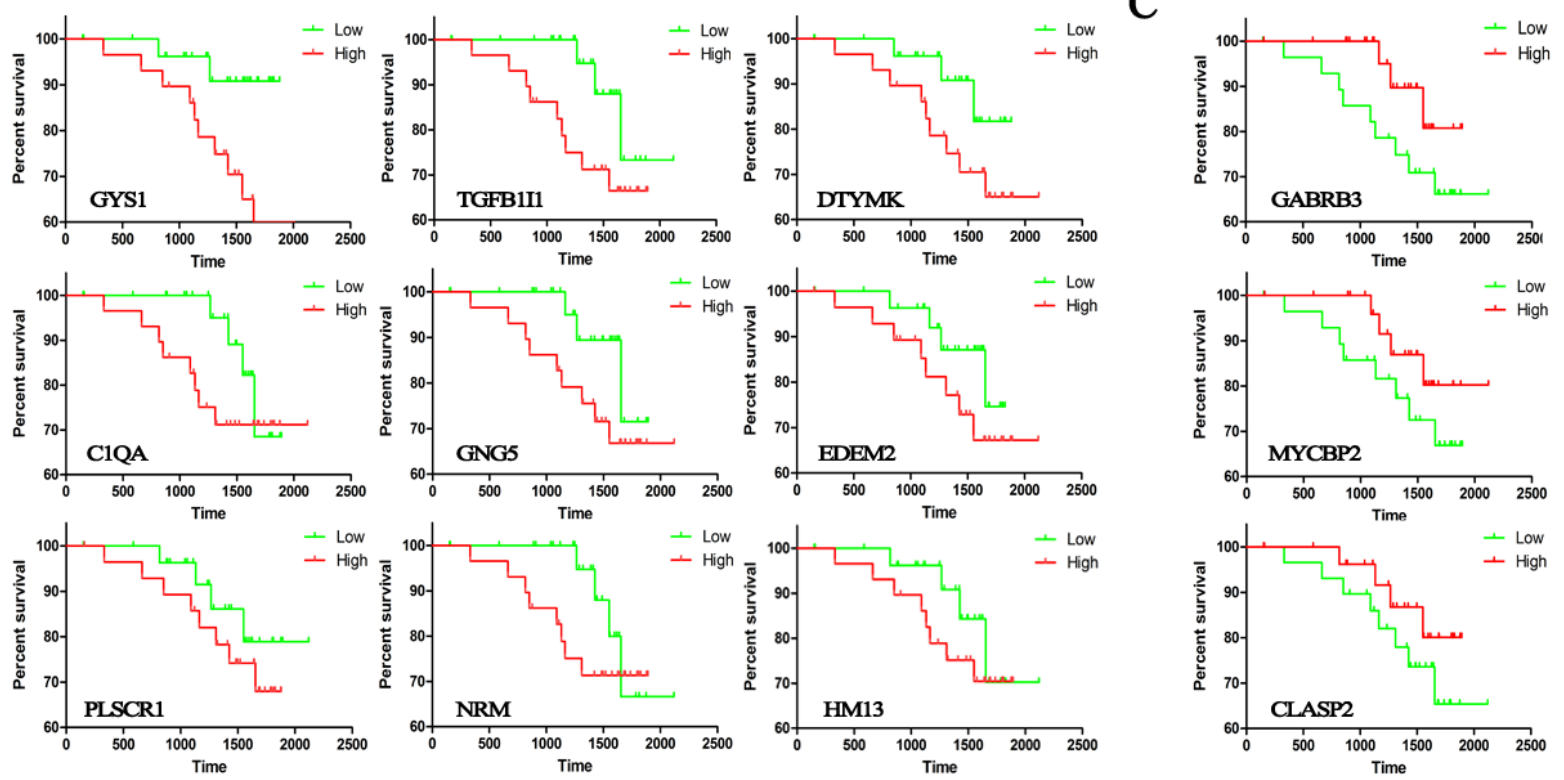

Figure 2: Heat maps were made from candidate genes on 5 NBTs, 58 AIIs and 8 AIIIs in CGGA dataset. (A) Transcripts levels of 29 candidate genes were identified in three databases and significantly increased with increasing grades (data on the other two databases are supplied in supplementary table 2); TCGA subtypes were given in different colors. Survival analysis was performed by Kaplan-meier plot on candidate genes: (B) up-regulated genes; (C) down-regulated genes.

\section{TGFB1I1 was validated on protein level and associated with grade progression and subtype transition}

Analysis of TGFB1I1 expression by IHC in independent tissue microarrays (5 NBTs, 64 AIIs and 34 AIIIs) provided a further level of evidence supporting the key role of TGFB1I1 in malignant progression of astrocytomas. The protein expression of TGFB1I1 was gradually increasing with increasing tumor grades (NBT vs AII at $p=0.003$; AII vs AIII at $p=0.003$ ) (Figure-4A and 4B). Importantly, as showed in Figure-4C, we were once again reminded that high expression of TGFB1I1 protein indicated a poor survival in patients with AII and AIII.

Moreover, the transcript level of TGFB1I1 is the highest in mesenchymal subtype in all three databases, suggesting that TGFB1I1 might be associated with increasing invasion and migration (Figure-4D). Indeed, we found that TGFB1I1 was significantly positively correlated with the invasive biomarkers, MMP-2 $\left(p=5.8 \mathrm{E}-39, \mathrm{R}^{2}=0.46\right)$ and MMP-9 $(p=1.7 \mathrm{E}-43$, $\mathrm{R}^{2}=0.43$ ) (supplementary Figure-2C). A significant positive correlation was observed between TGFB1I1 RNA and protein expression (Figure-4D, 4E and 4F). The fact 
A

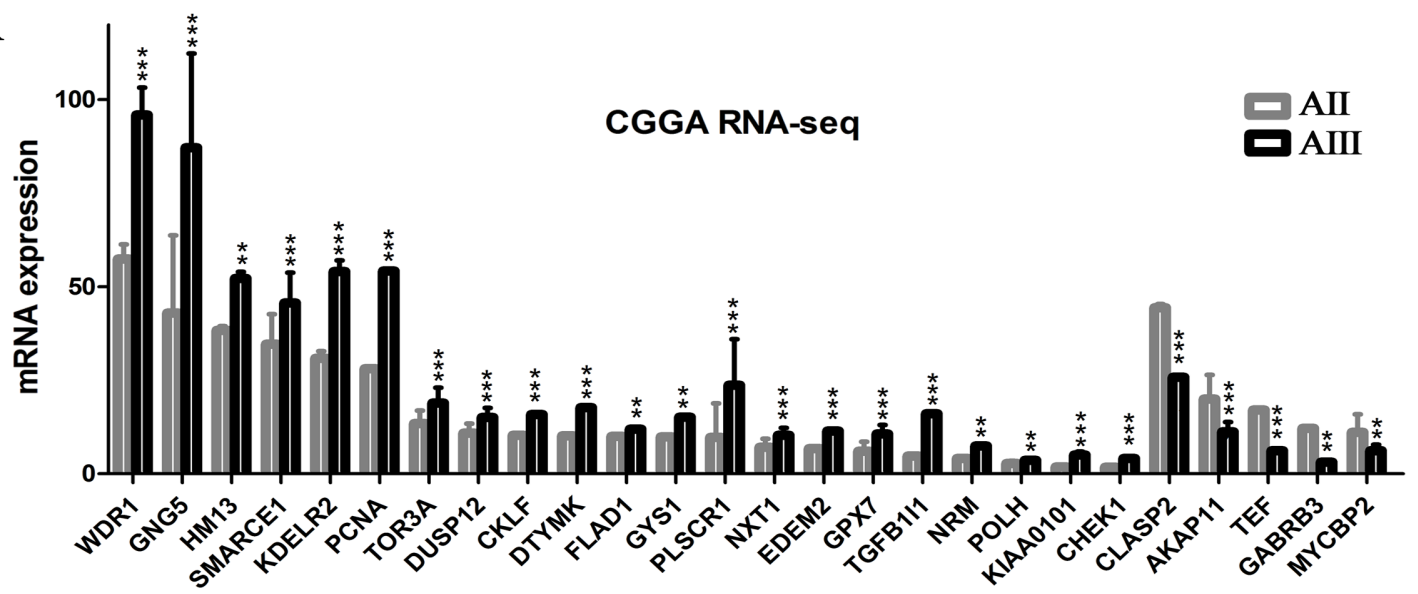

B
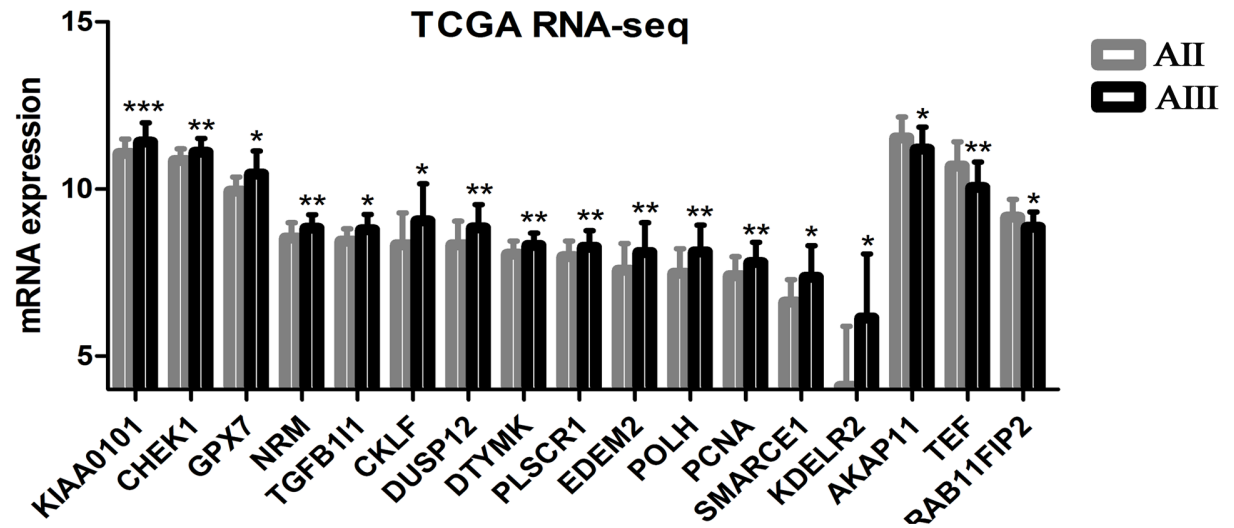

C

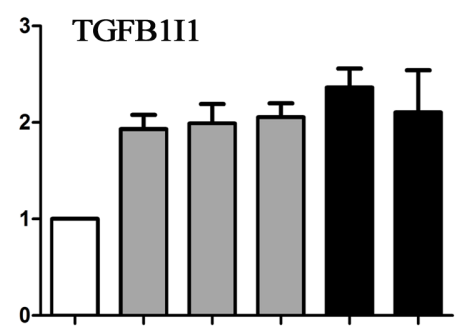

HA N1 N15 N18 N14 H4

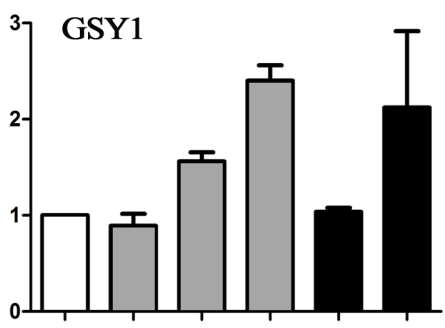

HA N1 N15 N18 N14 H4

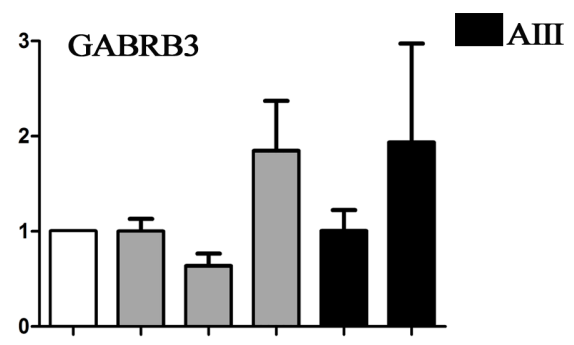

HA N1 N15 N18 N14 H4

$\mathrm{D}$
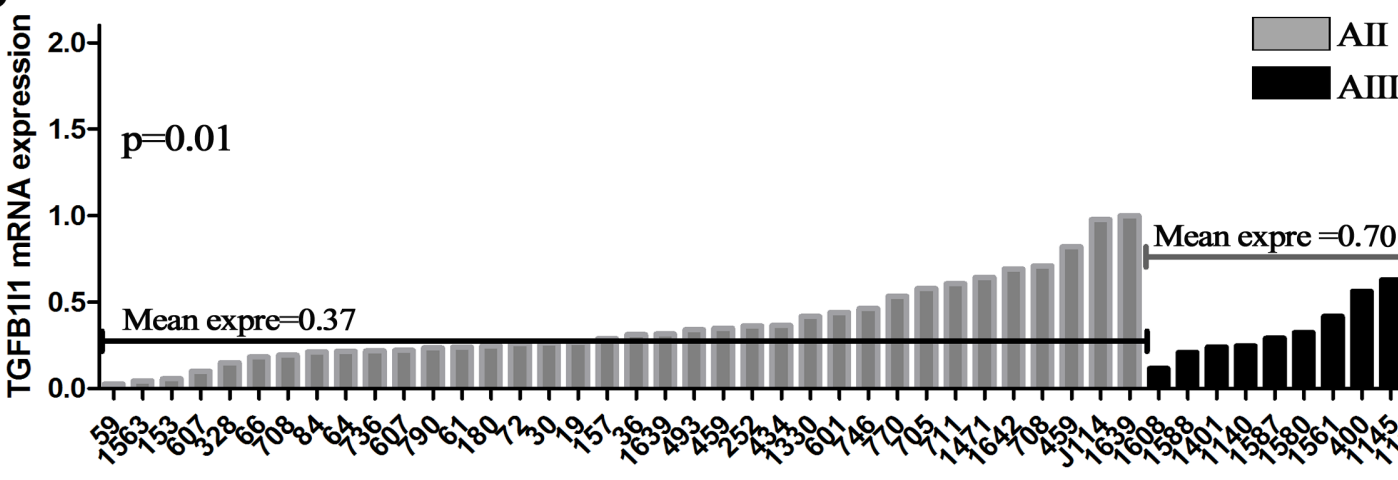

Mean expre $=0.70$

Figure 3: Candidate genes were confirmed on RNA-sequencing data and validated by qPCR. (A and B) The candidate genes obtained by analysis of microarrays were further confirmed on two RNA-seq database including 57 AII and 71 AIII (CGGA and TCGA); (C) The top 3 survival associated genes, GYS1, TGFB1I1 and GABRA3, were validated by qPCR in 6 cell lines ( 2 commercialized cell lines and 4 primary culture cells). (D) The expression level of TGFB1I1 was further validated on additional 49 samples (36 AIIs and 13 AIIIs). $* p<0.05, * * p<0.01,{ }^{* * *} p<0.001$ 

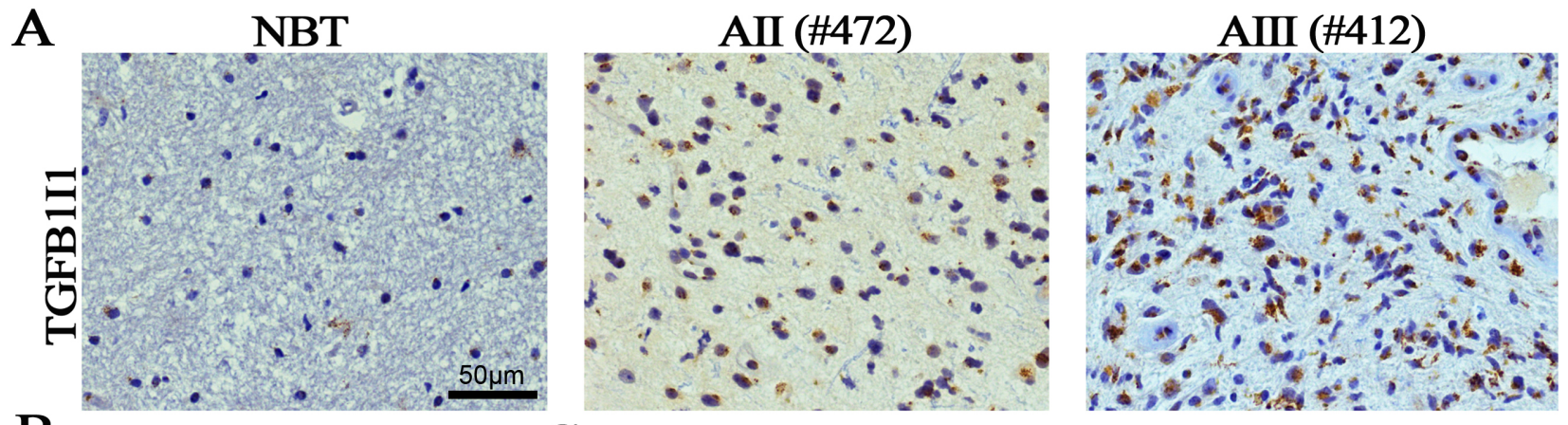

B

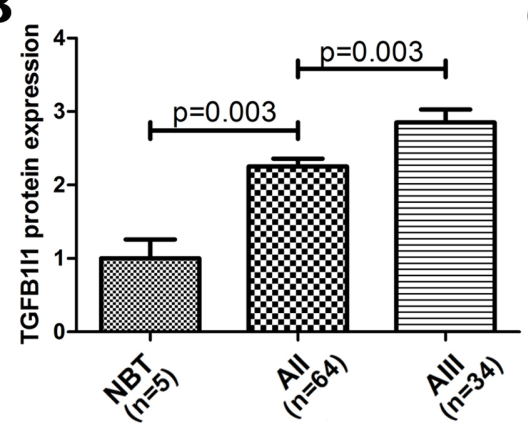

D



E

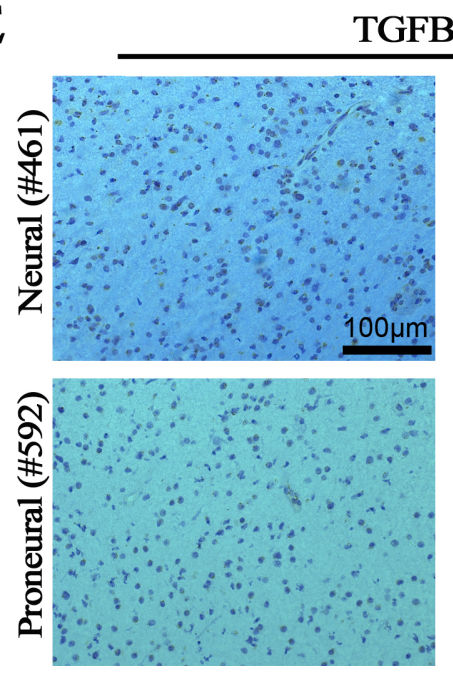

C

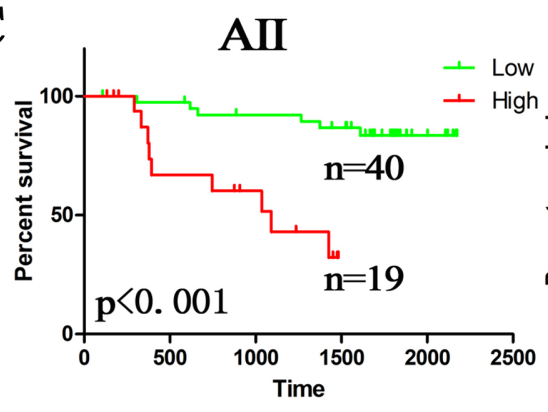

GSE16011

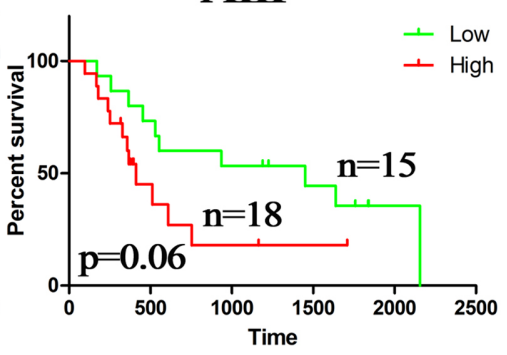

AIII
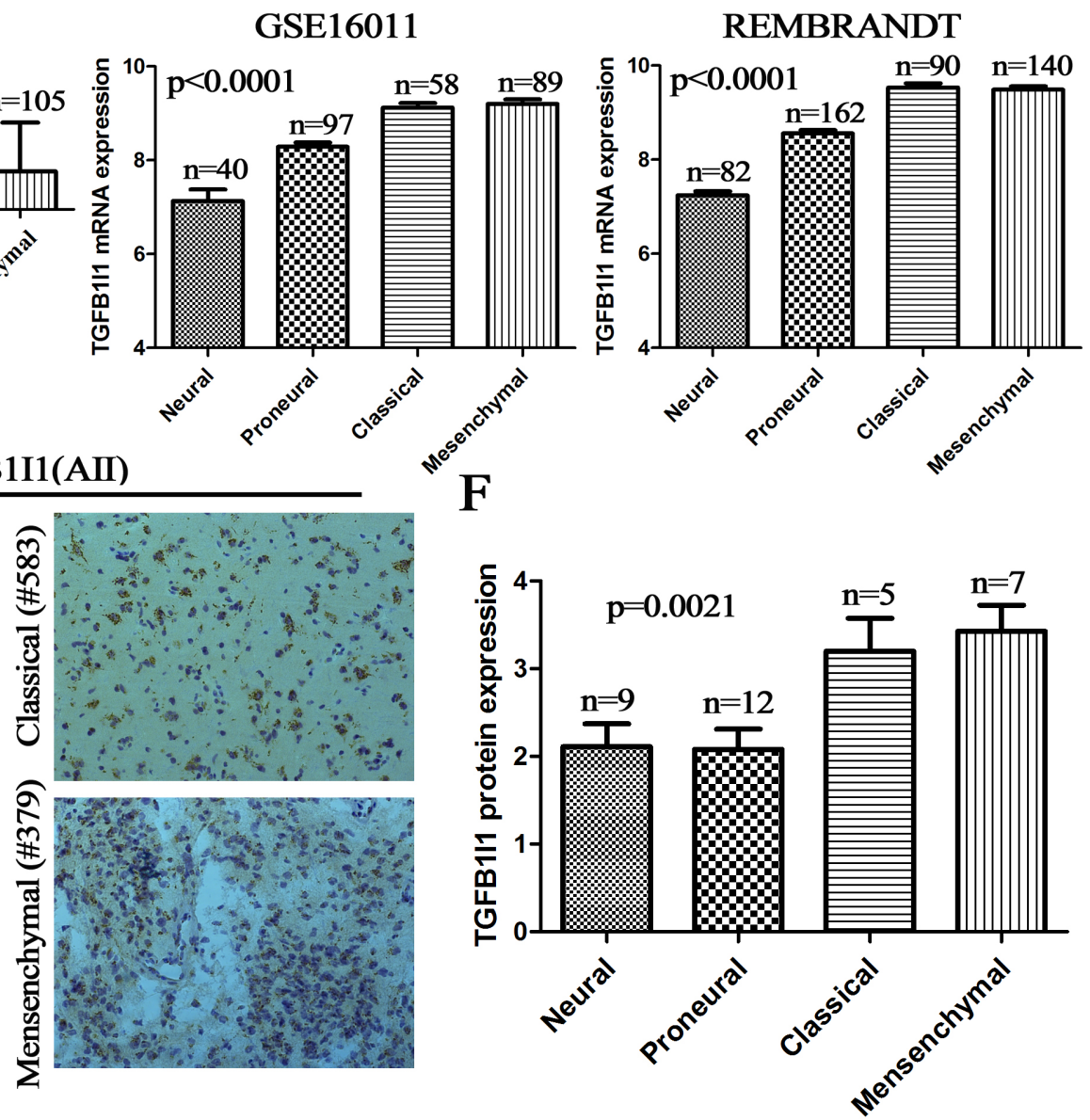

Figure 4: TGFB1I1 protein increased with grade progress and be associated with TCGA subtypes. (A and B) The protein expression of TGFB1I1 was detected in dependent tissue microarrays by IHC (5 NBTs, 64 AIIs and 34 AIIIs) and the expression level was assessed by semi-quantitative analysis; (C) High expression of TGFB1I1 protein indicated a poor survival in AII and AIII. (D and E) Either RNA level or protein level, TGFB1I1 was associated with TCGA subtypes and was the highest on mesenchymal subtype. 
that high expression of TGFB1I1 indicated a poor survival outcome suggests that TGFB1I1 might play important role in malignant progression of astrocytomas by driving cell invasion and migration.

\section{TGFB1I1 was required for TGF- $\beta$ stimulated EMT process}

TGF- $\beta 1$ is a classical driver for EMT process [19]. As an important regulator of TGF- $\beta$ signaling pathway, TGFB1I1 might play important role in TGF- $\beta$ stimulated EMT process. To confirm the role of TGFB1I1 in EMT process, we performed correlational analyses in 310 samples with genome expression in CGGA database (5 NBTs, 126 grade II, 51 grade III and 128 grade IV gliomas) and obtained a cluster of the top 308 genes (354 probes, supplementary table 5) which were significantly positively correlated with TGFB1I1 expression $\left(\mathrm{R}>0.6, p<10^{-30}\right)$. We then performed KEEG pathway analysis using the 308 TGFB1I1 associated genes (Figure-5A). We found that gene pathway terms were enriched for cell adhesion and ECM-receptor interaction that was consistent with the above pathway analysis.

In three databases, we found that there exists a significantly positive correlation between TGFB1I1 and TGF- $\beta 1$ (Figure-5B). To identify whether or not TGFB1I1 is induced by TGF- $\beta 1$ in EMT process, we detected TGFB1I1 and EMT markers using western blot and immunofluorescence in $\mathrm{H} 4$ and $\mathrm{U} 87$ cell lines which were treated with or without TGF- $\beta 1$ and TGFB1I1 shRNA (Figure-5C and 5E). The results revealed that TGFB1I1 was significantly increased in TGF- $\beta 1$ stimulated cells. Similarly, the protein expression of four master markers of EMT, N-cadherin, $\beta$-catenin, vimentin, and slug were remarkably elevated in TGF- $\beta 1$-stimulated cells. The invasive marker, MMP-2, was also increased in TGF$\beta 1$-stimulated cells. However, cells treated by TGFB1I1 shRNA displayed a significant reduction in these markers.
A

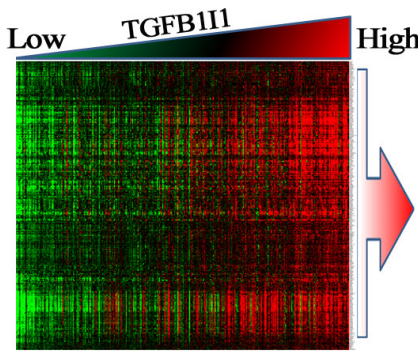

C
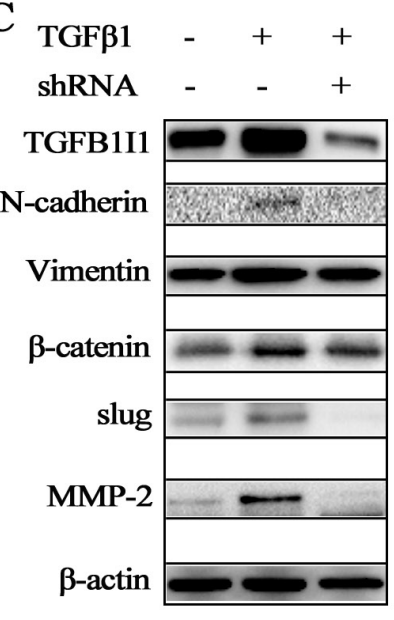

H4
Pathway analysis

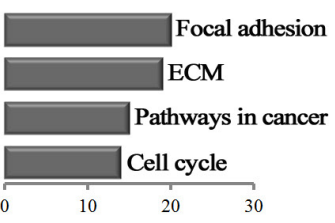

B

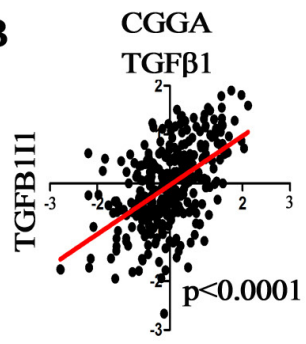

GSE16011

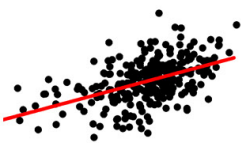

$\mathrm{p}<0.0001$
REMBRANDT

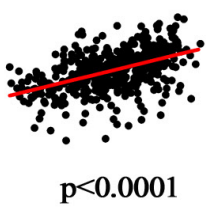

D
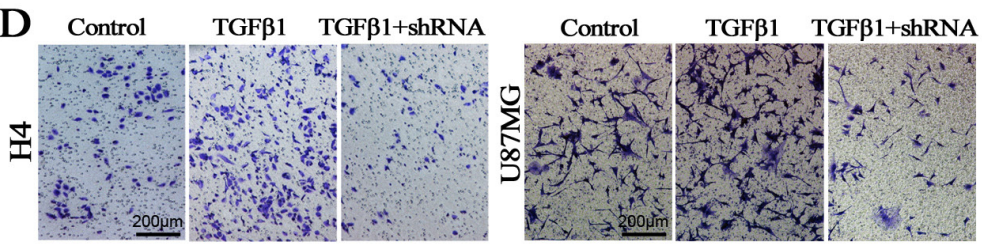

E
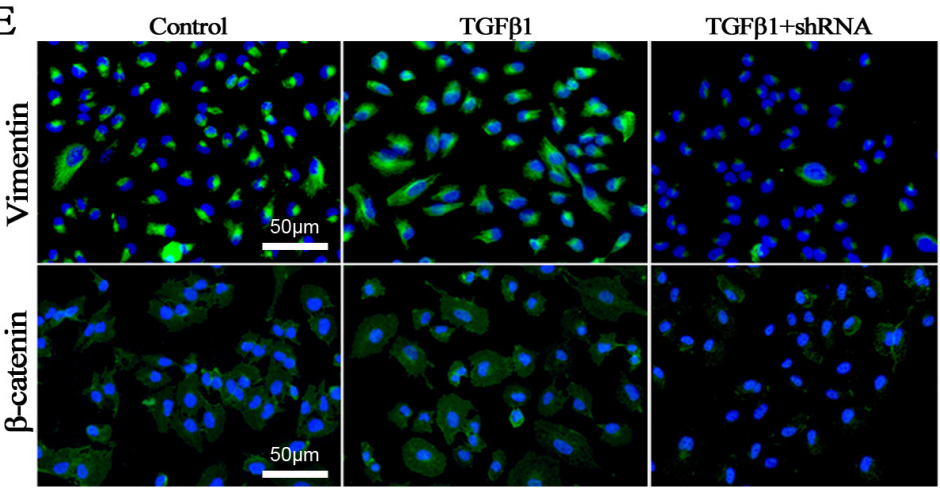

Figure 5: TGFB1I1 regulated TGF- $\beta 1$ induced EMT. (A) Correlation analysis performed in 310 samples with mRNA microarrays and a cluster of 308 TGFB1I1 associated genes were obtained ( $\mathrm{R}>0.6, p<10^{-30}$ ); Pathway analysis was performed using the 308 TGFB1I1 associated genes. (B) The expression level of TGFB1I1 was positively correlated with the expression level of TGF- $\beta 1$ in the three databases. (C and E) TGFB1I1 and EMT associated markers were significantly increased in TGF- $\beta 1$ stimulated cells and TGFB1I1 shRNA resulted in the decreasing expression of N-cadherin, vimentin, slug, $\beta$-catenin and MMP-2. (D) A significantly decreased invasion was observed in the TGFB1I1 shRNA treated cells compared with TGF- $\beta 1$ stimulated cells. $* p<0.05$ 
More importantly, a significantly decreased migration and invasion were observed in the TGFB1I1 shRNA treated cells compared with TGF- $\beta 1$ stimulated cells (Figure-5D and supplementary Figure-2A). TGF- $\beta 1$ stimulation also triggered EMT like morphological changes. TGF- $\beta 1$ treatment led to a pronounced increase of the mesenchymal like cells with elongated size and spindle phenotype (supplementary Figure 2B). TGFB1I1 shRNA transfection significantly counteracted the EMTlike alteration. Next, we examined whether the role of TGFB1I1 also occurs in animal model. U87 control and TGFB1I1 shRNA transfected U87 cells were injected into the brains of a total of 20 nude mice ( $n=10$ per group), and tumor formation was examined after 25 days. Among the 10 mice transplanted with parental U87 cells, 6 mice were found tumors in brains. Whereas, only 4 in the 10 mice transplanted with TGFB1I1 shRNA U87 cells were found tumors. Tumor volume with the TGFB1I1 shRNA was significantly smaller than did control mice (Figure-6B). More importantly, tumors with TGFB1I1 shRNA have a clearer boundary than control tumors with irregular and indefinite border (Figure-6A). Immunohistochemical analysis revealed decreased expression of EMT marker vimentin, $\beta$-catenin and MMP-2 in TGFB1I1 shRNA tumors (Figure-6C). These data hit yielded reproducible results that TGFB1I1 play a critical regulator in promoting tumor cell invasion and migration and TGFB1I1 is at least partially responsible for the TGF- $\beta$-induced EMT.

\section{DISCUSSION}

Malignant astrocytomas exhibit a relentless malignant progression characterized by widespread invasion throughout the brain. Most patients with low grade gliomas progress to high grade gliomas with increasing malignant degree. However, there also exists malignant progression in equal grade tumors that has been little investigated. The subtypes on the equal grade tumors, like mesenchymal and proneural subtype on GBM, can transit each other [20]. Understanding the mechanism of grade progression and subtypes transition and blocking the main oncogenic pathway are the crux of gliomas therapy. Increasing evidences showed that genetic alterations (mutation, deletion, amplification and overexpression) were involved in the genesis and progression of gliomas [21]. Established biomarkers of astrocytomas, such as TP53 and $I D H 1$ mutation, and even recently discovered TERT promoter mutations, were considered to be the early event of astrocytomas. In our data, TP53 and IDH1 mutation were as high as $50 \%$ and $80 \%$ in AII whereas only $28 \%$ and $39 \%$ in AIII. The frequency of IDHI and TP53 mutation in low-grade astrocytoams is similar (or even low) with that in AIII or secondary GBMs suggesting that these alterations might be not associated with the grade progression of astrocytomas (from AII to AIII, sGBM). These two alterations are rather rare in NBT but the highest frequency in AII suggesting that TP53 and IDHI mutations are among
A
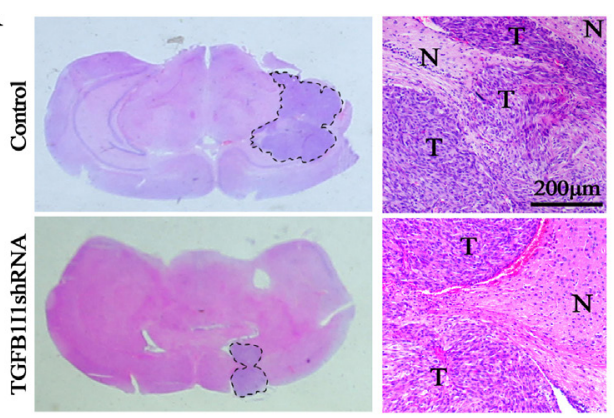

C
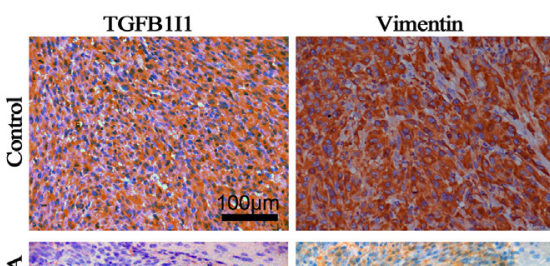

B

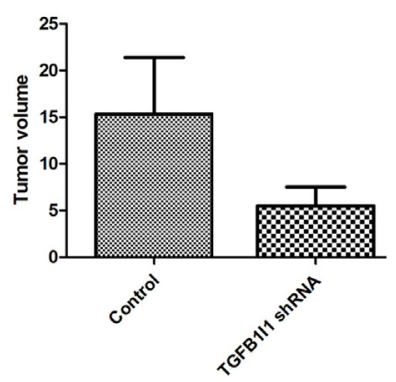

$\beta$-catenin

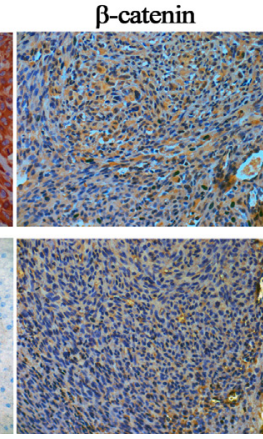

MMP-2

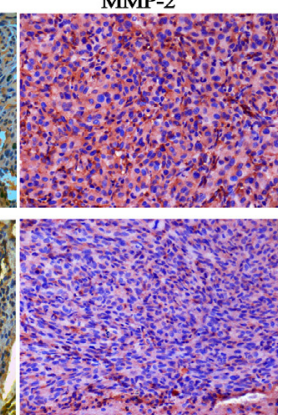

Figure 6: TGFB1I1 promoted tumor progression in vivo. (A and B) Tumor volume with the TGFB1I1 shRNA was significantly smaller than did control mice. $N($ control $)=6$ and $N($ TGFB1I1shRNA) $=4$ (C) Immunohistochemical staining for the 2 groups of mice, showing decreased vimentin, $\beta$-catenin and MMP-2 in mice injected with TGFB1I1 shRNA. 
early events in astrocytoma development (from NBT to AI or AII). Moreover, patients with $I D H 1$ mutation frequently possess TP53 mutation, indicating that this alteration was an earlier event in astrocytomas development than TP53 mutation. In addition, a small mutation frequency of PTEN, $5 \%$ reported in other teams, was detected in our samples ( $3.5 \%$ of AII and $17.6 \%$ of AIII); the increasing frequency with increasing grades indicates an important role of PTEN signaling in malignant progression of a small subgroup of astrocytomas.

To find the driver genes in malignant progression of astrocytomas, we collected 380 whole genome expression profiles (34 NBTs, 193 IIAs and 153 IIIAs) in three mRNA microarray databases and 2 RNA-sequence databases. Bioinformatics analysis of the RNA expression data followed by pathway analysis revealed that the EMT-associated pathways were most significantly altered along increasing tumor grades with up-regulation of 17 genes. All of the 17 candidate genes were significantly up-regulated with increasing tumor grade and associated with malignant phenotype in various tumors. PCNA and KIAA0101 were classical biomarkers in estimating malignant degree of tumor cells [16, 22]. PCNA, proliferating cell nuclear antigen, is involved in DNA replication and repair in proliferating cells; KIAA0101, a proliferating cell nuclear antigen (PCNA)-associated factor, is involved in the regulation of DNA repair, cell cycle progression, and cell proliferation. DTYMK is increased in the majority of lung adenocarcinomas and elevated DTYMK levels are correlated with poor survival [23]. TGFB1I1 has also been shown to function as an oncogene by inducing EMT to promote invasion in cancer cells as well as in normal breast epithelial cells [24]. Survival analysis showed high expression of these candidate genes indicates poor outcome of patients with astrocytomas. This comprehensive demonstration of these gene changes may serve as a model for studies to understand the complex mechanisms of astrocytomas progression.

Finally, through validation by qPCR and IHC, we focused on TGFB1I1, a critical regulator of EMT process. The activation of EMT program has been proposed as the critical mechanism for the acquisition of malignant phenotypes. Studies in vivo and in vitro have demonstrated that EMT contributes to tumor progression and subtypes transition [25]. Evidences showed that TGF- $\beta$ signaling is an important inducer of an EMT phenotype in cancer [19]. The central role played by TGF- $\beta$ in the EMT program is further illustrated by the actions of several TGF- $\beta$ inducing transcription factors that facilitate acquisition of a mesenchymal phenotype, such as SMAD, TGFB1I1, RhoA and $\beta$-catenin [26]. TGFB1I1, the TGF- $\beta$-induced focal adhesion protein, resulted in matrix degradation, cell migration, and invasion via Rac1 regulation of $\mathrm{p} 38$
MAPK in TGF- $\beta$-treated MCF10A cells [24]. Forced expression of TGFB1I1 is sufficient to induce cytoskeletal organization and led to the formation of ROCK-dependent actin stress fibers [17]. In addition, the promoter of TGFB1I1 contains a CArG element which could be bound by some exogenous factors [27]. TGFB1I1 can shuttle between the nucleus and cytoplasm through an oxidantsensitive nuclear export sequence by which TGFB1I1 can regulate some gene expression [28]. In our data, the RNA and protein levels of TGFB1I1 were significantly increased along with increasing astrocytoma grades and high expression of TGFB1I1 indicates a poor survival in patients with astrocytomas. Moreover, we found that high expression of TGFB1I1 might contribute to the malignant transition from endothelial-like phenotype to mesenchymal-like phenotype. The RNA and protein levels of TGFB1I1 were the highest in mesenchymal astrocytomas than others subtypes (neural, proneural and classical). By KEEG analysis, TGFB1I1 associated genes were involved in the regulation of cell adhesion and ECM-receptor interactions that were related to the EMT process. These data suggests that TGFB1I1 can promote migration and invasion during TGF- $\beta$-induced EMT. As expected, the expression level of TGF $\beta 1$ was significantly correlated with TGFB1I1. The invasive biomarkers of gliomas, MMP-2 and MMP-9, have also markedly positive correlation with TGFB1I1. TGF- $\beta 1$ stimulated induction of $\mathrm{N}$-cadherin, $\beta$-catenin, vimentin, slug and even MMP-2 can be blocked by introduction of a specific TGFB1I1 shRNA. The increasing migration and invasion in TGF- $\beta 1$ stimulated $\mathrm{H} 4$ and U87MG cell lines were also blocked by the shRNA plasmid. Finally, these results were further confirmed in vivo experiments.

In conclusion, this finding is new opportunity for understanding the fundamental basis for malignant progression of astrocytomas and the candidate genes might be novel interfering targets for astrocytomas therapy. Our data demonstrates that TGFB1I1 is required for TGF- $\beta$ stimulated EMT that contributes to malignant progression of astrocytomas. Blocking TGF- $\beta$ signal pathway by targeting TGFB1I1 might be an effective treatment for astrcytomas.

\section{METHODS AND MATERIALS}

\section{Samples}

Samples were obtained from the Chinese Glioma Genome Atlas (CGGA), including 6 NBTs, 217 AIIs and 40 AIIIs (supplementary table1). The mean age of diagnosis is 38.7 years ranging from 13 to 74 years in all levels of astrocytomas. Patients with AIII have a slightly later median age of onset of about 42.9 years. Males are slightly more commonly affected, with a male to female ratio of about 1.54:1. These samples were used to perform 
mRNA expression profiles, RNA-sequencing, detection of the established biomarkers, immunohistochemistry and survival analysis. The numbers of sample in each analysis were mentioned in following sections. Normal adult brain samples were obtained after informed consent from patients with severe traumatic brain injury who needed posttrauma surgery and from patients who had undergone surgery for primary epilepsy. All of the patients underwent surgical resection from January 2005 through December 2012. Patients were eligible for the study if their diagnosis was established histologically by 2 neuropathologists according to the 2007 WHO classification guidelines. Tumor tissue samples were obtained by surgical resection before patients underwent radiation and/or chemotherapy. Only samples with $80 \%$ tumor cells were selected for analysis. This study was approved by the institutional review boards of all hospitals involved in the study, and written informed consent was obtained from all patients.

\section{Cell culture and reagents}

The human astrocytoma cell lines H4, U87 and human astrocytes (HA) were obtained from the Institute of Biochemistry and Cell Biology, Chinese Academy of Science. Freshly resected tumor tissues (N1 and N15, primary culture AII cells; N18, primary culture grade II oligodendroastrocytoma; N14, primary culture grade III oligodendroastrocytoma cell) were enzymatically and mechanically dissociated into single cells and grown in DMEM/F12 media supplemented with B27 (Invitrogen), EGF $(20 \mathrm{ng} / \mathrm{ml})$, and bFGF $(20 \mathrm{ng} / \mathrm{ml})$. Cells were maintained in DMEM containing 10\% FBS, $50 \mathrm{U} / \mathrm{ml}$ penicillin $\mathrm{G}$, and $250 \mu \mathrm{g} / \mathrm{ml}$ streptomycin in a humidified atmosphere containing $5 \% \mathrm{CO}^{2}$ at $37^{\circ} \mathrm{C}$. For $\mathrm{TGF} \beta 1$ stimulation, cells were treated with $6 \mathrm{ng} / \mathrm{ml}$ TGF $\beta 1$ (Peprotech) for $24 \mathrm{~h}$ before assay.

\section{shRNA transfection}

H4 and U87MG cells were transfected with TGFB1I1 shRNA (a pool of 3 target-specific lentiviral vector plasmids, Santa Crusz, USA, sc-37685-SH) and control vector (sc-108060) with lipofectamine (Invitrogen) according to the manufacturer's instructions. Stably transfected cells were selected for with $0.5 \mu \mathrm{g} / \mathrm{ml}(\mathrm{H} 4)$ and $0.4 \mu \mathrm{g} / \mathrm{ml}$ (U87) puromycin (Invitrogen) for 2 weeks, after which clones were selected and amplified.

\section{Detection on the established biomarkers}

Genomic DNA was isolated from frozen tumor tissues by using the QIAamp DNA Mini Kit (Qiagen). The genomic region spanning wild-type R132 of IDH1 (182 AIIs and 33 AIIIs) and MGMT promoter methylation (23 AIIs and 24 AIIIs) were analyzed by pyrosequencing (QIAGEN, Germany). PTEN (140 AIIs and 17 AIIIs) and TP53 mutation (149 AIIs and 18 AIIIs) was identified by exon direct sequencing and sanger sequencing, respectively. EGFR amplificantion and 1p19q loss (6 NBTs, 217 AIIs, and 40 AIIIs) was identified by fluorescence in situ hybridization (FISH).

\section{RNA expression data}

Our whole-genome mRNA expression microarray data (5 NBTs, 58 AIIs, 8 AIIIs) and RNA-sequencing data (35 AIIs and 13 AIIIs) were deposited in the CGGA database. The other two whole-genome mRNA expression microarray data were downloaded from the repository for molecular brain neoplasia data (REMBRANDT, http://caintegrator- info.nci.nih.gov/ rembrandt: 21 NBTs, 65 AIIs and 58 AIIIs) and GSE16011 data (http: //www.ncbi.nlm.nih.gov/geo/query/acc. cgi? acc $=$ GSE 16011: 8 NBTs, 13 IIAs and 16 IIIAs). TCGA (The Cancer Genome Atlas) RNA-sequencing data was downloaded from TCGA database (http: //cancergenome. nih. gov: 22 AIIs and 58 AIIIs).

\section{qPCR}

The expression levels of TGFB1I1, GSY1 and GABRB3 in 6 cell lines and 49 samples were analyzed with real-time quantitative PCR using the SYBR Supermix Kit (Bio-Rad, Hercules, CA). PCR included the following components: $100 \mathrm{nM}$ each primer, diluted cDNA templates, and iQ SYBR Green supermix. PCR efficiency was examined by serially diluting the template cDNA, and the melting curve data were collected to check PCR specificity. Each cDNA sample was run as triplicates. The GAPDH primer was included in every plate to avoid sample variations. The relative mRNA level was presented as unit values of $2^{\wedge}[\mathrm{Ct}(\mathrm{GAPDH})-\mathrm{Ct}$ (gene of interest) $]$. The primer sequences for TGFB1I1, GSY1 and GABRB3 are listed in Supplementary Table 4.

\section{Immunohistochemistry and immunocytofluorescent}

Immunohistochemistry (IHC) of paraffin sections in tissue microarrays and immunocytofluorescent (IF) in H4 cell line were performed as previously described [29]. Briefly, the sections were incubated with primary antibody, TGFB1I1 (Santa Crusz, 1:200 dilution), beta-catenin and vimentin (Cell Signaling Technology, 1:200 dilution), MMP-2 (ABCAM at a concentration of $5 \mu \mathrm{g} / \mathrm{ml}$ ) overnight at $4{ }^{\circ} \mathrm{C}$, then incubated with a biotinylated secondary antibody (1:200 dilution) at room temperature for $1 \mathrm{~h}$, followed by the incubation with ABC-peroxidase reagent (1:200 dilution, Vector, USA) for an additional $1 \mathrm{~h}$. After washing with Tris-buffer, the sections were stained with DAB for $5 \mathrm{~min}$, rinsed in water and counterstained with hematoxylin. IF was performed 
on H4 cell line. Briefly, cells were incubated with primary antibody for $1 \mathrm{~h}$ at room temperature. FITC-labeled secondary antibodies were added at 1:100 dilution, and the cells were then incubated for another $30 \mathrm{~min}$. Nuclei were stained with 4,6-diamidino-2-phenylindole (DAPI; Invitrogen).

\section{Western blot}

Whole-cell lysates were prepared using RIPA buffer. Equal amounts of total protein $(30 \mu \mathrm{g})$ from cell lysates were loaded on a $10 \% \mathrm{SDS} / \mathrm{PAGE}$ gel, transferred to a PVDF membrane (Millipore), and detected using an ECL Western Blotting Detection System (Biorad). Antibodies were primary antibodies TGFB1I1 (Santa Crusz, 1:500) $\mathrm{N}$-cadherin, beta-catenin, slug, vimentin (Cell Signaling Technology, 1:1000 dilution) and MMP-2 (ABCAM, at a concentration of $5 \mu \mathrm{g} / \mathrm{ml}$ ). $\beta$-actin (sigma, 1:5000 dilution) was used as the loading control. Secondary antibodies used were goat anti-rabbit IgG-HRP and goat anti-mouse IgG-HRP (Zhongshan Gold Bridge Biotechnology).

\section{Invasion assay}

Transwell invasion assays were performed using transwell filters (Costar, USA) coated with Matrigel (3.9 $\mu \mathrm{g} / \mu \mathrm{l}, \quad 60-80 \mu \mathrm{l})$ on the upper surface of the polycarbonic membrane (diameter $6.5 \mathrm{~mm}$, pore size $8 \mu \mathrm{m}$ ). A total of $1 \times 10^{5}$ cells were plated onto the upper chamber of the transwell plates with $2 \%$ FBS in DMEM. To the lower chambers of the wells was added 10\% FBS in DMEM. Following $24 \mathrm{~h}$ incubation, the non-invading cells were removed from the upper surfaces of the invasion membranes and the cells on the lower surface were stained with crystal violet. The average number of cells per field was determined by counting cells in 6 random fields per well.

\section{Wound assay}

Cells were grown in 6-well plates with complete medium. After $90 \%$ confluence was reached, the wound was created by a germ-free $100 \mu$ pipette tip in the monolayer. The cells were washed with PBS and grown in $2 \%$ FBS media for $24 \mathrm{~h}$. The wounds were observed under a phase contrast microscope (IX81, Olympus). The images were analysed by drawing lines at the wound edges. The width of the scratch was measured at $0,8,18$ and $24 \mathrm{~h}$ post-treatment.

\section{Vivo experiment}

$\mathrm{BALB} / \mathrm{c}$ female athymic mice were implanted in the brain with U87 wild-type and shRNA transfected cells. Briefly, mice were anesthetized with 5\% chloral hydrate and cells were implanted using cranial guide screws as previously described [30]. A TJ-4A Syringe Pump Controller and microinfusion syringe pump (1 $\mu \mathrm{l} / \mathrm{min})$ were used to implant $3 \times 10^{6}$ cells into the brain of mice. Mice were sacrificed after 25 days simultaneously. Brains were extracted and fixed in 10\% formalin for 24 hours, embedded in paraffin, and sectioned into $5 \mu \mathrm{m}$ slices

\section{Statistical analysis}

SPSS version 13.0 was used for all statistical analyses. Differentially expression genes were detected by unpaired Student's t-test. The $\chi^{2}$ test was applied for statistical analysis of the correlation for 2 independent variables. KaplanMeier survival analysis was used to estimate the survival distributions. The log-rank test was applied to assess the statistical significance between stratified survival groups using the GraphPad Prism version 4.0 statistical software. KEGG pathway and GO analysis was performed using DAVID (http://david.abcc.ncifcrf.gov/). Heat maps of different grade astrocytomas were constructed by Gene Cluster 3.0 and Gene Tree View software. A two-sided $p$ value $<0.05$ was regarded as significant.

\section{Funding}

This work was supported by grants from Beijing science and technology plan (No.Z131100006113018), National Science Foundation of China (No. 91229121), National Natural Science Foundation of China (No. 81201993) and Foundation for Beijing Institute of Brain Disorders (BIBD-PXM2013_014226_07_000084).

\section{Disclose any potential conflicts of interest}

The authors disclose no conflicts of interest

\section{REFERENCES}

1. Nakazato Y. [the 4th Edition of WHO Classification of Tumours of the Central Nervous System published in 2007]. No Shinkei Geka. 2008; 36:473-491.

2. Verhaak RG, Hoadley KA, Purdom E, Wang V, Qi Y, Wilkerson MD, Miller CR, Ding L, Golub T, Mesirov JP, Alexe G, Lawrence M, O'Kelly M, Tamayo P, Weir BA, Gabriel S, Winckler W, Gupta S, Jakkula L, Feiler HS, Hodgson JG, James CD, Sarkaria JN, Brennan C, Kahn A, Spellman PT, Wilson RK, Speed TP, Gray JW, Meyerson M, Getz G, Perou CM, Hayes DN. Integrated genomic analysis identifies clinically relevant subtypes of glioblastoma characterized by abnormalities in PDGFRA, IDH1, EGFR, and NF1. Cancer Cell. 2010; 17:98-110.

3. Yan W, Zhang W, You G, Zhang J, Han L, Bao Z, Wang Y, Liu Y, Jiang C, Kang C, You Y, Jiang T. Molecular classification of gliomas based on whole genome gene 
expression. A systematic report of 225 samples from the Chinese Glioma Cooperative Group. Neuro Oncol. 2012; 14: 1432-1440.

4. Lin Y, Chen Y, Wang Y, Yang J, Zhu VF, Liu Y, Cui X, Chen L, Yan W, Jiang T, Hergenroeder GW, Fletcher SA, Levine JM, Kim DH, Tandon N, Zhu JJ, Li M. ZIP4 is a novel molecular marker for glioma. Neuro Oncol. 2013; 15:1008-1016.

5. Dunlap SM, Celestino J, Wang H, Jiang R, Holland EC, Fuller GN, Zhang W. Insulin-like growth factor binding protein 2 promotes glioma development and progression. Proc Natl Acad Sci U S A. 2007; 104:11736-11741.

6. Yan H, Parsons DW, Jin G, McLendon R, Rasheed BA, Yuan W, Kos I, Batinic-Haberle I, Jones S, Riggins GJ, Friedman H, Friedman A, Reardon D, Herndon J, Kinzler KW, Velculescu VE, Vogelstein B, Bigner DD. IDH1 and IDH2 mutations in gliomas. N Engl J Med. 2009; 360:765-773.

7. Ichimura K, Bolin MB, Goike HM, Schmidt EE, Moshref A, Collins VP. Deregulation of the p14ARF/MDM2/p53 pathway is a prerequisite for human astrocytic gliomas with G1-S transition control gene abnormalities. Cancer Res. 2000; 60:417-424.

8. Kim YH, Lachuer J, Mittelbronn M, Paulus W, Brokinkel B, Keyvani K, Sure U, Wrede K, Nobusawa S, Nakazato Y, Tanaka Y, Vital A, Mariani L, Ohgaki H. Alterations in the RB1 pathway in low-grade diffuse gliomas lacking common genetic alterations. Brain Pathol. 2011; 21: 645-651.

9. Jiao Y, Killela PJ, Reitman ZJ, Rasheed AB, Heaphy CM, de Wilde RF, Rodriguez FJ, Rosemberg S, Oba-Shinjo SM, Nagahashi MS, Bettegowda C, Agrawal N, Lipp E, Pirozzi C, Lopez G, He Y, Friedman H, Friedman AH, Riggins GJ, Holdhoff M, Burger P, McLendon R, Bigner DD, Vogelstein B, Meeker AK, Kinzler KW, Papadopoulos N, Diaz LA, Yan H. Frequent ATRX, CIC, FUBP1 and IDH1 mutations refine the classification of malignant gliomas. Oncotarget. 2012; 3:709-722.

10. Verhaak RG, Hoadley KA, Purdom E, Wang V, Qi Y, Wilkerson MD, Miller CR, Ding L, Golub T, Mesirov JP, Alexe G, Lawrence M, O'Kelly M, Tamayo P, Weir BA, Gabriel S, Winckler W, Gupta S, Jakkula L, Feiler HS, Hodgson JG, James CD, Sarkaria JN, Brennan C, Kahn A, Spellman PT, Wilson RK, Speed TP, Gray JW, Meyerson M, Getz G, Perou CM, Hayes DN. Integrated genomic analysis identifies clinically relevant subtypes of glioblastoma characterized by abnormalities in PDGFRA, IDH1, EGFR, and NF1. Cancer Cell. 2010; 17:98-110.

11. Ohgaki H, Kleihues $\mathrm{P}$. The definition of primary and secondary glioblastoma. Clin Cancer Res. 2013; 19: 764-772.

12. Yao Y, Chan AK, Qin ZY, Chen LC, Zhang X, Pang JC, Li HM, Wang Y, Mao Y, Ng HK, Zhou LF. Mutation analysis of IDH1 in paired gliomas revealed IDH1 mutation was not associated with malignant progression but predicted longer survival. PLoS One. 2013; 8:e67421.

13. Huang DW, Sherman BT, Lempicki RA. Systematic and integrative analysis of large gene lists using DAVID bioinformatics resources. Nat Protoc. 2009; 4:44-57.

14. Guan X, Vengoechea J, Zheng S, Sloan AE, Chen Y, Brat DJ, O'Neill BP, de Groot J, Yust-Katz S, Yung WK, Cohen ML, Aldape KD, Rosenfeld S, Verhaak RG, Barnholtz-Sloan JS. Molecular subtypes of glioblastoma are relevant to lower grade glioma. PLoS One. 2014; 9:e91216.

15. Liu Y, Marks K, Cowley GS, Carretero J, Liu Q, Nieland TJ, Xu C, Cohoon TJ, Gao P, Zhang Y, Chen Z, Altabef AB, Tchaicha JH, Wang X, Choe S, Driggers EM, Zhang J, Bailey ST, Sharpless NE, Hayes DN, Patel NM, Janne PA, Bardeesy N, Engelman JA, Manning BD, Shaw RJ, Asara JM, Scully R, Kimmelman A, Byers LA, Gibbons DL, Wistuba II, Heymach JV, Kwiatkowski DJ, Kim WY, Kung AL, Gray NS, Root DE, Cantley LC, Wong KK. Metabolic and functional genomic studies identify deoxythymidylate kinase as a target in LKB1-mutant lung cancer. Cancer Discov. 2013; 3:870-879.

16. Yu P, Huang B, Shen M, Lau C, Chan E, Michel J, Xiong Y, Payan DG, Luo Y. P15(PAF), a novel PCNA associated factor with increased expression in tumor tissues. Oncogene. 2001; 20:484-489.

17. Tumbarello DA. Turner CE. Hic-5 contributes to epithelialmesenchymal transformation through a RhoA/ROCKdependent pathway. J Cell Physiol. 2007; 211:736-747.

18. Pignatelli J, Tumbarello DA, Schmidt RP. Turner CE. Hic-5 promotes invadopodia formation and invasion during TGFbeta-induced epithelial-mesenchymal transition. J Cell Biol. 2012; 197:421-437.

19. Song J. EMT or apoptosis: A decision for TGF-beta. Cell Res. 2007; 17:289-290.

20. Bhat KP, Balasubramaniyan V, Vaillant B, Ezhilarasan R, Hummelink K, Hollingsworth F, Wani K, Heathcock L, James JD, Goodman LD, Conroy S, Long L, Lelic N, Wang S, Gumin J, Raj D, Kodama Y, Raghunathan A, Olar A, Joshi K, Pelloski CE, Heimberger A, Kim SH, Cahill DP, Rao G, Den Dunnen WF, Boddeke HW, Phillips HS, Nakano I, Lang FF, Colman H, Sulman EP, Aldape K. Mesenchymal differentiation mediated by NF-kappaB promotes radiation resistance in glioblastoma. Cancer Cell. 2013; 24:331-346.

21. Altieri R, Agnoletti A, Quattrucci F, Garbossa D, Calamo SF, Bozzaro M, Fornaro R, Mencarani C, Lanotte M, Spaziante R, Ducati A. Molecular biology of gliomas: Present and future challenges. Transl Med UniSa. 2014; 10:29-37.

22. Hosokawa M, Takehara A, Matsuda K, Eguchi H, Ohigashi H, Ishikawa O, Shinomura Y, Imai K, Nakamura Y, Nakagawa H. Oncogenic role of KIAA0101 interacting with proliferating cell nuclear antigen in pancreatic cancer. Cancer Res. 2007; 67:2568-2576. 
23. Liu Y, Marks K, Cowley GS, Carretero J, Liu Q, Nieland TJ, Xu C, Cohoon TJ, Gao P, Zhang Y, Chen Z, Altabef AB, Tchaicha JH, Wang X, Choe S, Driggers EM, Zhang J, Bailey ST, Sharpless NE, Hayes DN, Patel NM, Janne PA, Bardeesy N, Engelman JA, Manning BD, Shaw RJ, Asara JM, Scully R, Kimmelman A, Byers LA, Gibbons DL, Wistuba II, Heymach JV, Kwiatkowski DJ, Kim WY, Kung AL, Gray NS, Root DE, Cantley LC, Wong KK. Metabolic and functional genomic studies identify deoxythymidylate kinase as a target in LKB1-mutant lung cancer. Cancer Discov. 2013; 3:870-879.

24. Pignatelli J, Tumbarello DA, Schmidt RP. Turner CE. Hic-5 promotes invadopodia formation and invasion during TGFbeta-induced epithelial-mesenchymal transition. J Cell Biol. 2012; 197:421-437.

25. Mahabir R, Tanino M, Elmansuri A, Wang L, Kimura T, Itoh T, Ohba $Y$, Nishihara $H$, Shirato $H$, Tsuda $M$, Tanaka S. Sustained elevation of Snail promotes glialmesenchymal transition after irradiation in malignant glioma. Neuro Oncol. 2013.

26. Kalluri R, Weinberg RA. The basics of epithelialmesenchymal transition. J Clin Invest. 2009; 119:1420-1428.
27. Wang X, Hu G, Betts C, Harmon EY, Keller RS, Van De Water L, Zhou J. Transforming growth factor-beta1induced transcript 1 protein, a novel marker for smooth muscle contractile phenotype, is regulated by serum response factor/myocardin protein. J Biol Chem. 2011; 286:41589-41599.

28. Shibanuma M, Kim-Kaneyama JR, Ishino K, Sakamoto N, Hishiki T, Yamaguchi K, Mori K, Mashimo J, Nose K. Hic-5 communicates between focal adhesions and the nucleus through oxidant-sensitive nuclear export signal. Mol Biol Cell. 2003; 14:1158-1171.

29. Liu Y, Yan W, Zhang W, Chen L, You G, Bao Z, Wang Y, Wang H, Kang C, Jiang T. MiR-218 reverses high invasiveness of glioblastoma cells by targeting the oncogenic transcription factor LEF1. Oncol Rep. 2012; 28:1013-1021.

30. Shi Z, Zhang J, Qian X, Han L, Zhang K, Chen L, Liu J, Ren Y, Yang M, Zhang A, Pu P, Kang C. AC1MMYR2, an inhibitor of dicer-mediated biogenesis of Oncomir miR-21, reverses epithelial-mesenchymal transition and suppresses tumor growth and progression. Cancer Res. 2013; 73: 5519-5531. 